\title{
Crops are a main driver for species diversity and the toxigenic potential of Fusarium isolates in maize ears in China
}

\author{
H. Zhang ${ }^{1}$, B. Brankovics ${ }^{2,3}$, W. Luo ${ }^{1}$, J. Xu ${ }^{1}$, J.S. Xu ${ }^{1}$, C. Guo ${ }^{4}$, J.G. Guo ${ }^{4}$, S.L. Jin ${ }^{4}$, W.Q. Chen ${ }^{1 *}$, J. Feng ${ }^{1 *}$, A.D. Van \\ Diepeningen ${ }^{2}$, T.A.J. Van der Lee ${ }^{5}$ and C. Waalwijk ${ }^{5}$ \\ ${ }^{1}$ State Key Laboratory for Biology of Plant Diseases and Insect Pests, Institute of Plant Protection, Chinese Academy of \\ Agriculture Sciences, No. 2 West Yuanmingyuan Road, 100193 Beijing, China P.R.; ${ }^{2}$ CBS-KNAW Fungal Biodiversity \\ Centre, Uppsalalaan 8, 3584 CT Utrecht, the Netherlands; ${ }^{3}$ Institute for Biodiversity and Ecosystem Dynamics, University \\ of Amsterdam, P.O. Box 94216, 1090 GE Amsterdam, the Netherlands; ${ }^{4}$ Institute of Plant Protection, Gansu Academy of \\ Agriculture Sciences, 730070 Lanzhou, China P.R.; ${ }^{5}$ Wageningen University and Research Center, Plant Research International, \\ B.U. Biointeractions E Plant Health, P.O. Box 16,6700 AA, the Netherlands; wqchen@ippcaas.cn; ifeng@ippcaas.cn
}

Received: 19 October 2015 / Accepted: 25 April 2016

(c) 2016 Wageningen Academic Publishers

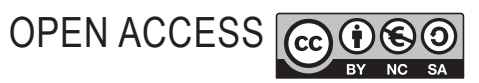

RESEARCH ARTICLE

\begin{abstract}
In recent years increasing demands and the relatively low-care cultivation of the crop have resulted in an enormous expansion of the acreage of maize in China. However, particularly in China, Fusarium ear rot forms an important constraint to maize production. In this study, we showed that members of both the Fusarium fujikuroi species complex (FFSC) and the Fusarium graminearum species complex are the causal agents of Fusarium ear rot in the main maize producing areas in China. Fumonisin producing Fusarium verticillioides was the most prevalent species, followed by fumonisin producing Fusarium proliferatum and 15-acetyldeoxynivalenol producing F. graminearum. Both Fusarium temperatum and Fusarium boothii were identified for the first time in the colder regions in China, extending their known habitats to colder environments. Mating type analysis of the different heterothallic FFSC species, showed that both types co-occur in each sampling site suggestive of the possibility of sexual recombination. Virulence tests with F. boothii (from maize) and F. graminearum from maize or wheat showed adaptation to the host. In addition, F. graminearum seems to outcompete $F$. boothii in wheat-maize rotations. Based on our findings and previous studies, we conclude that wheat/maize rotation selects for $F$. graminearum, while a wheat/rice rotation selects for $F$. asiaticum. In contrast, $F$. boothii is selected when maize is cultivated without rotation. A higher occurrence of F. temperatum is observed on maize in colder climatological regions in China, while Fusarium meridionale seems restricted to mountain areas. Each of these species has their characteristic mycotoxin profile and deoxynivalenol and fumonisin are the potential threats to maize production in Northern China.
\end{abstract}

Keywords: fumonisin production, Fusarium fujikuroi species complex, Fusarium graminearum species complex, increasing maize production, trichothecene production

\section{Introduction}

China is the second largest maize production country in the world. In recent years, both the yield and acreage of maize increased rapidly, surpassing rice and now maize has become the largest grain crop in China (data from China's National Bureau of Statistics). However, ear rot diseases caused by Fusarium spp. are a serious constraint on maize production. Fusarium spp. not only cause a high economic loss every year in maize and small grain cereal production, but also accumulation of mycotoxins (mainly fumonisins and trichothecenes) in resulting crops (Bottalico, 1998). These mycotoxins are a significant risk to food safety and animal health, because they cause mycotoxicoses in animals and humans (Marasas, 2001; Ueno et al., 1973).

Fusarium species are responsible for at least two kinds of maize ear rot. Customarily, disease caused by members 
of the Fusarium graminearum species complex (FGSC) is known as Gibberella or red ear rot, and ear rot caused by the members of Fusarium fujikuroi species complex (FFSC) is known as Fusarium or pink ear rot. However, 'Fusarium' is advocated as the sole name for a group of fungi that includes virtually all Fusarium species of importance in plant pathology, mycotoxicology, medicine, and basic research (Geiser et al., 2013). To avoid confusion, in this report, we use Fusarium ear rot (FER) as the sole disease name to represent maize ear rot caused by Fusarium species including both members of FGSC as well as FFSC.

Members of the FGSC are some of the most frequently isolated causal agents of Fusarium head blight (FHB) of wheat and barley and FER of maize (Boutigny et al., 2011; Ward et al., 2008; Yang et al., 2008). Phylogenetic species recognition, with genealogical concordance, has provided strong evidence that FGSC comprises at least 16 distinct species. On maize in South Africa only Fusarium boothii was found (Boutigny et al., 2011). In Nepal, the predominant species on maize were Fusarium meridionale and Fusarium asiaticum (Desjardins and Proctor, 2011), while F. meridionale was also predominant in Argentina (Sampietro et al., 2011). In South Korea, four species within the FGSC were associated with FER and F. graminearum was predominant (Lee et al., 2012). A similar situation was also found in France and Italy, where F. graminearum was the main causal agents of FER (Boutigny et al., 2014; Somma et al., 2014). Within the FGSC there are three types of trichothecene mycotoxin producers (chemotypes): (1) nivalenol (NIV) producers and acetylated derivatives; (2) deoxynivalenol (DON) and 3-acetyldeoxynivalenol (3-ADON); and (3) DON and 15-acetyldeoxynivalenol (15-ADON; Miller et al., 1991). The vast majority of $F$. graminearum isolates reported on maize in France, Korea and China were 15-ADON producers (Boutigny et al., 2014; Lee et al., 2012; Ndoye et al., 2012) while in Europe a small population of NIV producers was found (Boutigny et al., 2014; Ndoye et al., 2012; Somma et al., 2014). Most F. asiaticum on maize in Asia produce NIV (Desjardins and Proctor, 2011; Lee et al., 2012; Ndoye et al., 2012), while $F$. meridionale and $F$. boothii isolates seem to be fixed for NIV and 15-ADON production, respectively. This is comparable to reports from samplings in South Africa, Nepal and Argentina (Boutigny et al., 2011; Desjardins and Proctor, 2011; Sampietro et al., 2011). In China, Ndoye et al. (2012) reported that on maize F. asiaticum with the NIV chemotype dominated in warmer regions while $F$. graminearum with the 15 -ADON chemotype is dominant in cooler regions.

In many countries, members of the FFSC are the most important causal agent of maize ear rot. In contrast, on wheat and barley members of the FFSC are of minor importance and disease is mostly caused by members of the FGSC. Therefore, with the increase of maize cultivation the ratio of FFSC to FGSC species in fields may change. Molecular systematics has revealed that FFSC includes at least 50 distinct species, many of which are pathogens of both plants and human (Kvas et al., 2009). Many FFSC species can produce fumonisins, a family of mycotoxins, causing various diseases in animals, and it has been associated epidemiologically with oesophageal cancer as well as neural tube defects in some human populations (Gelderblom et al., 1988; Marasas et al., 2004). In maize, Fusarium verticillioides, Fusarium proliferatum and Fusarium subglutinans are the most prevalent species worldwide (Adejumo et al., 2007; Aguin et al., 2014; Madania et al., 2013; Qiu et al., 2015; Torres et al., 2001). The first two species are potential fumonisin producers (Logrieco et al., 2002), while F. subglutinans is generally believed to be a fumonisin non-producer as the fumonisin biosynthetic genes are absent (Proctor et al., 2004). Fusarium temperatum is a newly described species first found on maize in Belgium. It is closely related to $F$. subglutinans, but showed a different mycotoxin profile, especially for beauvericin production (Fumero et al., 2015; Scauflaire et al., 2012).

In China, most studies about species composition and population dynamics focus on Fusarium isolates from barley and wheat (Yang et al., 2008; Zhang et al., 2012). There are a few, partially conflicting, reports on maize. Ndoye et al. (2012) concluded that on maize the NIV chemotype of $F$. asiaticum is predominant in southern China and the 15ADON chemotype of F. graminearum in northern China. However, the methodology applied by these researchers does not allow sufficient species discriminatio. Qiu et al. (2015) found fumonisin producing $F$. verticillioides to be the most prevalent on maize in southern provinces Jiangsu and Zhejiang, but these are no main maize producing areas. So a detailed description of all Fusarium species causing FER in the main maize producing areas in China is still unknown. Demonstrating which Fusarium spp. and their chemotypes occur in maize will help to understand the nature of recent FER outbreaks and mycotoxin contaminations, and thus is essential for developing effective strategies for preventing disease and mycotoxin contamination in agricultural products.

The objectives of this research were to study the cause of FER on maize in the major maize producing areas in China, now that maize has become the largest cereal crop. Specifically, we (1) characterised this population at the species level and studied the distribution of the different species over the various regions, (2) determined the potential mycotoxins produced by these Fusarium species, (3) compared the variation in pathogenicity of FGSC species from wheat and maize to analyse their host preference and (4) discuss the influence of agronomic and climatic conditions on the distribution of Fusarium spp. and associated mycotoxins. 


\section{Materials and methods}

\section{Fungal isolates}

Diseased maize ears with pink or white spore mass, which were collected from 53 sampling sites in 6 provinces of China in 2013 (Figure 1), were used for isolation of Fusarium strains. Diseased seeds were surface sterilised in 70\% ethanol for $30 \mathrm{~s}$, and immediately immersed in 10\% sodium hypochlorite for $90 \mathrm{~s}$, after which the kernels were extensively rinsed with sterile distilled water. After drying on sterile filter paper, the seeds were placed on potato dextrose agar (PDA) plates (Chen et al., 2009). After 3 days of incubation at $28{ }^{\circ} \mathrm{C}$, newly grown-out mycelium was transferred onto a fresh medium to generate uniform mycelial colonies. All Fusarium isolates were purified using the single-spore isolation method as previously described (Zhang et al., 2012). To prevent re-isolation of the same isolate only one isolate was preserved from each maize cob after single-spore isolation. Single spore cultures were stored in $15 \%$ dimethyl sulfoxide (DMSO) at $-80{ }^{\circ} \mathrm{C}$. In order to compare the variation in pathogenicity of Fusarium from different hosts, we included fifteen $F$. graminearum isolates collected from wheat heads in a previous study (Zhang et $a l ., 2012)$ in the pathogenicity test. These isolates were collected in Hebei $(n=7)$, Shandong $(n=2)$, Heilongjiang $(n=2)$, Shaanxi $(n=2)$ and Henan $(n=2)$ respectively.

\section{Species determination}

Fungal isolates were inoculated on PDA and incubated at $28^{\circ} \mathrm{C}$ for 5 days. Mycelia were harvested, freeze-dried and ground to a fine powder using a MiniBeadbeater-96 system (BioSpec, Bartlesville, OK, USA). Genomic DNA was extracted with E.Z 96 ${ }^{\mathrm{m}}$ Fungal DNA Kit (Omega Bio-tec, Inc., Norcross, GA, USA) according to the manufacturer's instructions. After that, part of the translation elongation factor gene (TEF-1 $\alpha, \sim 700 \mathrm{bp}$ ) was amplified and sequenced as previously described (Geiser et al., 2004). The strains were identified by sequence comparison with the FUSARIUM-ID database (http://isolate.fusariumdb.org) and at GenBank (http://blast.ncbi.nlm.nih.gov).

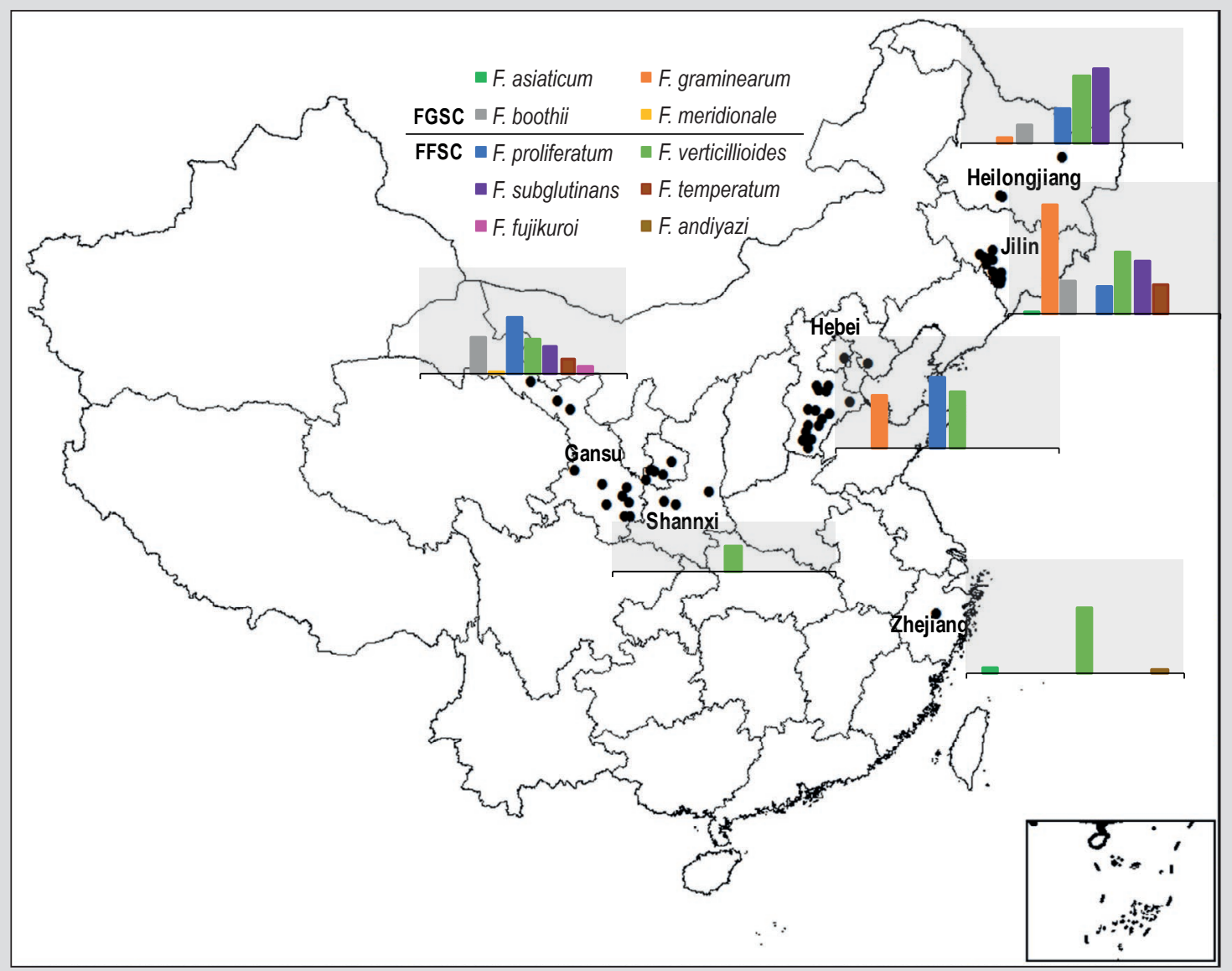

Figure 1. Map of China indicating the 175 sampling sites in 15 provinces. Coloured bars represent the numbers of isolates obtained in each province. 


\section{Phylogenetic and gene diversity analysis}

Genetic diversity parameters of the TEF-1 $\alpha$ gene were calculated using the program DnaSP (Librado and Rozas, 2009), including haplotypes, number of segregating sites, number of parsimony informative sites between alleles and haplotypic diversity. Phylogenetic analyses of TEF-1 $\alpha$ gene were performed with MEGA5.2 for maximum likelihood analysis using default settings (Tamura et al., 2011). The reliability of these tree topologies was evaluated using bootstrap support with 1000 pseudo replicates of the data.

\section{Chemotype and mating types identification}

Isolates of FGSC were classified into NIV, 3-ADON, and 15 -ADON chemotype by multiplex PCR using primers sets based on Tri3 and Tri12 gene sequences (Ward et al., 2008). To assess the ability of FFSC isolates to produce fumonisins, the presence of the FUM1 genes was checked by PCR amplification using primer sets Fum-1/Fum-2 (Baird et al., 2008) and Fum-3/Fum-4 (Bluhm et al., 2002). Primer sets Gfmat1a/Gfmat1b and Gfmat2c/Gfmat2d were used to identify the mating type (MAT-1 or -2) of FFSC strains (Steenkamp et al., 2000). Primers used in this study are listed in Table 1.

\section{Pathogenicity test}

To compare the pathogenicity of $F$. graminearum isolates from wheat (Fg-wheat), F. graminearum isolates from maize (Fg-maize) and $F$. boothii isolates from maize (Fbmaize), fifteen isolates were selected randomly from each population. Medium resistant cultivar Yangmai 158 was selected for the pathogenicity on wheat. It was planted in three different blocks according to normal agronomic practices. At anthesis, ten heads in each block were inoculated by injecting $20 \mu \mathrm{l}$ conidia suspension $\left(10^{6}\right.$ conidia $/ \mathrm{ml}$ ) of each individual isolate into the floral cavity of the central floret of a spike (Zhang et al., 2012). A total of 30 heads was injected by a single strain. Pathogenicity was assessed as the incidence of infected spikelets (IIS). The IIS was determined visually by counting the number of infected spikelets per head 14 days after inoculation and was expressed as percentage of total spikelets.

The pathogenicity of Fusarium isolates on maize stalks was tested by toothpick inoculation as described previously (Scauflaire et al., 2012). Zhengdan 958, the most widely grown maize variety in China, was planted in three different blocks. The 45 strains were cultured in $15-\mathrm{ml}$ tubes containing 15 triple autoclaved toothpicks and 5 $\mathrm{ml}$ potato dextrose broth medium (PDB; Difco, Franklin Lakes, NJ, USA), and incubated for 2 weeks at $28^{\circ} \mathrm{C}$ in the dark. One day before plant inoculation, the toothpicks were removed from the tubes and air-dried in a sterile bench. Five 7-week-old maize plants per block were selected and the stalks were inoculated at approximately $10 \mathrm{~cm}$ above ground by insertion of toothpicks inoculated with single isolate. The toothpick was cut at the stalk surface and the stalk was sealed with Parafilm ${ }^{\text {Tw }}$ (Bemis NA, Neenah, WI, USA). After 11 days of growth the plants were harvested and the stalks were cut longitudinally with a sterile knife flanking the inoculation point. The length of the necrotic region in the stalk was measured. A total of 15 replicates

Table 1. List of polymerase chain reaction (PCR) primers used in this study.

\begin{tabular}{|c|c|c|c|}
\hline Primer & Sequence $\left(5^{\prime}\right.$ to $\left.3^{\prime}\right)$ & Target (PCR fragment length) & Reference \\
\hline EF1 & ATGGGTAAGGA(A/G)GACAAGAC & TEF-1a, 700 bp & Geiser et al., 2004 \\
\hline EF2 & GGA(G/A)GTACCAGT(G/C)ATCATGTT & & \\
\hline $3 \mathrm{CON}$ & TGGCAAAGACTGGTTCAC & Tri3 & Ward et al., 2008 \\
\hline $3 N A$ & GTGCACAGAATATACGAGC & 840 bp NIV & \\
\hline $3 D 15 A$ & ACTGACCCAAGCTGCCATC & 610 bp $15-A D O N$ & \\
\hline 3D3A & CGCATTGGCTAACACATG & 243 bp 3-ADON & \\
\hline $12 \mathrm{CON}$ & CATGAGCATGGTGATGTC & Tri12 & Ward et al., 2008 \\
\hline $12 \mathrm{NF}$ & TCTCCTCGTTGTATCTGG & 840 bp NIV & \\
\hline $12-15 F$ & TACAGCGGTCGCAACTTC & 670 bp 15-ADON & \\
\hline $12-3 F$ & CTTTGGCAAGCCCGTGCA & 410 bp 3-ADON & \\
\hline Fum-1 & GTCCTACGCGATACATCCCACCACAAT & FUM1, 419 bp & Baird et al., 2008 \\
\hline Fum-2 & GATCAAGCTCGGGGCCGTCGTTCATAG & & \\
\hline Fum-3 & GTCGAGTTGTTGACCACTGCG & FUM1, 845 bp & Bluhm et al., 2002 \\
\hline Fum-4 & CGTATCGTCAGCATGATGTAGC & & \\
\hline Gfmat1a & GTTCATCAAAGGGCAAGCG & MAT-1, 200 bp & Steenkamp et al., 2000 \\
\hline Gfmat1b & TAAGCGCCCTCTTAACGCCTTC & & \\
\hline Gfmat2c & AGCGTCATTATTCGATCAAG & MAT-2, 800 bp & \\
\hline Gfmat2d & CTACGTTGAGAGCTGTACAG & & \\
\hline
\end{tabular}


were performed for each strain. The data analysis was done with the statistical software SAS v8 (SAS Institute Inc., Cary, NC, USA).

\section{Results}

\section{Fusarium species associated with maize ear rot}

A total of 395 isolates was collected from 53 sampling sites in six provinces in 2013 (Table 2, Figure 1). The detailed information of species composition in each sampling site is summarised in Table 3. Heilongjiang and Jilin Province are in northeast China and have a very cold and dry climate (annual average temperature is $3 \sim 5^{\circ} \mathrm{C}$, and the minimum temperature in winter is about $-30 \sim-40^{\circ} \mathrm{C}$ ). The planting system results in one harvest per year. Hebei Province is in the North China Plain, where the annual average temperature is $10 \sim 12{ }^{\circ} \mathrm{C}$. Maize-wheat rotation alternating per year dominates this region. The provinces Shaanxi and Gansu are in northwest China, the south part of this region, where our samples were collected is a little warmer than Hebei. In the south part of Gansu, wheat and maize are sometimes grown in the same area and crop rotation occurs within the same year. These five provinces are important maize producing areas in China producing roughly $40 \%$ of the nation's output. Furthermore, we collected diseased ears from a breeding nursery in Dongyang County in Zhejiang Province in Eastern China and south of the Yangtze River, where the acreage of maize is very small. This region is warm and humid; the annual average temperature is about $17^{\circ} \mathrm{C}$.
Based on the results of TEF-1 $\alpha$ gene sequence alignments against the FUSARIUM-ID and GenBank databases, a total of ten different Fusarium species was detected, which could be classified into two species complexes: FFSC $(\mathrm{n}=283,71.65 \%)$ and FGSC ( $\mathrm{n}=112,28.35 \%)$ (Table 2). Six of the identified species belonged to FFSC, of which $F$. verticillioides was the dominant one that was found in all six provinces with a total of 120 isolates (30.38\%). We identified 76 F. proliferatum isolates (19.24\%) in five provinces. The sister species F. subglutinans and F. temperatum co-occurred in both northeast and northwest China with a number of 63 $(15.95 \%)$ and $20(5.06 \%)$ isolates respectively. The remaining 4 strains within FFSC were identified as Fusarium fujikuroi $(\mathrm{n}=3,0.76 \%)$ and Fusarium andiyazi $(\mathrm{n}=1,0.25 \%)$. Among the 112 members of the FGSC, four species were identified including F. graminearum $(\mathrm{n}=70,17.72 \%)$, F. boothii $(\mathrm{n}=38$, $9.62 \%)$, . asiaticum $(\mathrm{n}=3,0.76 \%)$ and $F$. meridionale $(\mathrm{n}=1$, $0.25 \%$ ). The species composition in each province was quite distinct: F. subglutinans dominated the most northern province Heilongjiang and the isolation frequency of $F$. graminearum was the highest in the neighbouring province Jilin, F. proliferatum was predominant in the provinces Hebei and Gansu and almost all isolates in Shaanxi and Zhejiang, were F. verticillioides (Figure 1).

Comparing only the provinces with larger sampled populations ( $\mathrm{n}>50)$, we found that F. graminearum was absent in Gansu, where F. boothii was the predominant FGSC species, while $F$. boothii was not isolated in Hebei province, where F. graminearum was the sole FGSC species isolated (Table 2).

Table 2. Geographical origin, numbers and species of Fusarium populations from maize.

\begin{tabular}{|c|c|c|c|c|c|c|c|c|c|c|c|c|}
\hline & \multirow[t]{2}{*}{$\begin{array}{l}\text { Sampling } \\
\text { sites }\end{array}$} & \multirow[t]{2}{*}{ Numbers } & \multicolumn{4}{|c|}{$\begin{array}{l}\text { Fusarium graminearum species } \\
\text { complex }\end{array}$} & \multicolumn{6}{|c|}{ Fusarium fujikuroi species complex } \\
\hline & & & 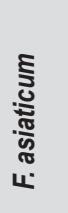 & 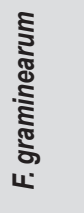 & 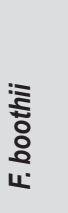 & 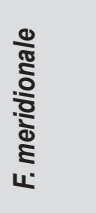 & 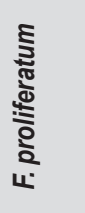 & 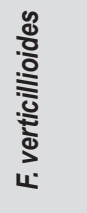 & 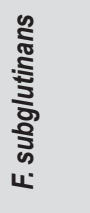 & 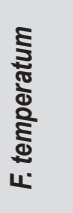 & 产 & 六 \\
\hline Heilongjiang & 3 & 69 & 0 & 2 & 6 & 0 & 12 & 23 & 26 & 0 & 0 & 0 \\
\hline Jilin & 12 & 142 & 1 & 49 & 15 & 0 & 12 & 28 & 24 & 13 & 0 & 0 \\
\hline Gansu & 17 & 84 & 0 & 0 & 17 & 1 & 27 & 16 & 13 & 7 & 3 & 0 \\
\hline Shaanxi & 3 & 10 & 0 & 0 & 0 & 0 & 0 & 10 & 0 & 0 & 0 & 0 \\
\hline Hebei & 17 & 64 & 0 & 19 & 0 & 0 & 25 & 20 & 0 & 0 & 0 & 0 \\
\hline Zhejiang & $1^{\mathrm{a}}$ & 26 & 2 & 0 & 0 & 0 & 0 & 23 & 0 & 0 & 0 & 1 \\
\hline Total & 53 & 395 & 3 & 70 & 38 & 1 & 76 & 120 & 63 & 20 & 3 & 1 \\
\hline Percentage & & & 0.76 & 17.72 & 9.62 & 0.25 & 19.24 & 30.38 & 15.95 & 5.06 & 0.76 & 0.25 \\
\hline
\end{tabular}


Table 3. The distribution of Fusarium isolates in sampling sites.

\begin{tabular}{|c|c|c|c|c|c|c|c|c|c|c|c|c|c|c|c|c|}
\hline & $\begin{array}{l}\text { Sampling } \\
\text { sites }\end{array}$ & Latitude & Longitude & 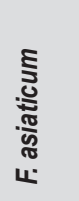 & 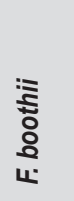 & 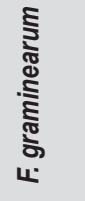 & 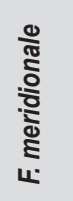 & 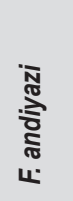 & 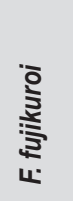 & 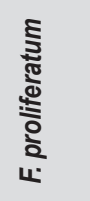 & 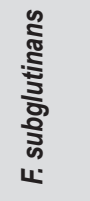 & 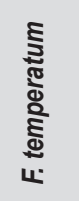 & 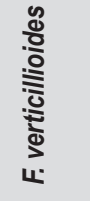 & 푱 & ئ & $\begin{array}{l}\mathscr{W} \\
\text { 丩 }\end{array}$ \\
\hline \multirow[t]{3}{*}{ Heilongjiang } & Yumisuo & $45^{\circ} 41^{\prime} 17.18^{\prime}$ & $126^{\circ} 37^{\prime} 11.91^{\prime}$ & & 6 & 2 & & & & 7 & 15 & & 11 & 41 & 8 & 61 \\
\hline & Zhibaosuo & $45^{\circ} 43^{\prime} 43.10^{\prime}$ & $126^{\circ} 30^{\prime} 51.37^{\prime}$ & & & & & & & 2 & 11 & & 4 & 17 & & \\
\hline & Jiamusi & $46^{\circ} 46^{\prime} 41.71^{\prime}$ & $130^{\circ} 25^{\prime} 44.74^{\prime}$ & & & & & & & 3 & & & 8 & 11 & & \\
\hline \multirow[t]{12}{*}{ Jilin } & Kaoshan & $43^{\circ} 22^{\prime} 28.20^{\prime}$ & $125^{\circ} 01^{\prime} 59.78^{\prime}$ & & & 1 & & & & 3 & 9 & 3 & & 16 & 65 & 77 \\
\hline & Yitong & $43^{\circ} 18^{\prime} 21.17^{\prime}$ & $125^{\circ} 22^{\prime} 31.51^{\prime}$ & & & & & & & 2 & 7 & 3 & & 12 & & \\
\hline & Fucai & $43^{\circ} 12^{\prime} 32.88^{\prime}$ & $125^{\circ} 29^{\prime} 17.81^{\prime}$ & & & & & & & & & & 7 & 7 & & \\
\hline & Changchun & $43^{\circ} 37^{\prime} 38.20^{\prime}$ & $125^{\circ} 35^{\prime} 12.15^{\prime}$ & & & 1 & & & & 2 & & & & 3 & & \\
\hline & Meihekou & $42^{\circ} 38^{\prime} 31.21^{\prime}$ & $125^{\circ} 50^{\prime} 36.54^{\prime}$ & & & 8 & & & & 3 & 6 & 4 & 2 & 23 & & \\
\hline & Jinhua & $42^{\circ} 22^{\prime} 20.11^{\prime}$ & $125^{\circ} 46^{\prime} 23.03^{\prime}$ & & 4 & 5 & & & & & 1 & 3 & & 13 & & \\
\hline & Tonghua & $42^{\circ} 13^{\prime} 49.73^{\prime}$ & $125^{\circ} 40^{\prime} 53.47^{\prime}$ & 1 & 2 & 5 & & & & & & & 1 & 9 & & \\
\hline & Hongmeizhen & $42^{\circ} 19^{\prime} 04.87^{\prime}$ & $125^{\circ} 32^{\prime} 01.07^{\prime}$ & & 5 & 9 & & & & & & & 2 & 16 & & \\
\hline & Dongfeng & $42^{\circ} 29^{\prime} 40.24^{\prime}$ & $125^{\circ} 26^{\prime} 52.74^{\prime}$ & & & & & & & & & & 9 & 9 & & \\
\hline & Dongliao & $42^{\circ} 45^{\prime} 47.98^{\prime}$ & $125^{\circ} 22^{\prime} 27.39^{\prime}$ & & & 11 & & & & & & & & 11 & & \\
\hline & Jianan & $43^{\circ} 05^{\prime} 51.74^{\prime}$ & $125^{\circ} 05^{\prime} 10.72^{\prime}$ & & 4 & 5 & & & & 2 & 1 & & & 12 & & \\
\hline & Gongzhuling & $43^{\circ} 30^{\prime} 43.52^{\prime}$ & $124^{\circ} 48^{\prime} 38.24^{\prime}$ & & & 4 & & & & & & & 7 & 11 & & \\
\hline \multirow[t]{17}{*}{ Gansu } & Longxi & $34^{\circ} 59^{\prime} 10.94^{\prime}$ & $104^{\circ} 28^{\prime} 43.12^{\prime}$ & & & & & & & & 1 & & & 1 & 18 & 66 \\
\hline & Zhangye & $38^{\circ} 55^{\prime} 16.49^{\prime}$ & $100^{\circ} 30^{\prime} 3.42^{\prime}$ & & & & & & & 1 & & & & 1 & & \\
\hline & Wuwei & $37^{\circ} 55^{\prime} 50.13^{\prime}$ & $102^{\circ} 39^{\prime} 7.32^{\prime}$ & & & & & & & & & & 5 & 5 & & \\
\hline & Zhenyuan & $35^{\circ} 29^{\prime} 45.41^{\prime}$ & $107^{\circ} 30^{\prime} 2.75^{\prime}$ & & 2 & & & & & 1 & & & 2 & 5 & & \\
\hline & Qingcheng & $36^{\circ} 1 ' 8.42^{\prime}$ & $107^{\circ} 52^{\prime} 34.54^{\prime}$ & & & & & & & 3 & & & & 3 & & \\
\hline & Yongchang & $38^{\circ} 14^{\prime} 42.83^{\prime}$ & $101^{\circ} 59^{\prime} 18.90^{\prime}$ & & & & & & & & 2 & & & 2 & & \\
\hline & Linxia & $35^{\circ} 28^{\prime} 12.97^{\prime}$ & $103^{\circ} 3^{\prime} 44.23^{\prime}$ & & & & & & & & & 4 & & 4 & & \\
\hline & Qincheng & $34^{\circ} 19^{\prime} 16.39^{\prime}$ & $105^{\circ} 49^{\prime} 20.25^{\prime}$ & & 1 & & & & & 1 & 4 & & & 6 & & \\
\hline & Liuping & $34^{\circ} 53^{\prime} 47.27^{\prime}$ & $105^{\circ} 43^{\prime} 33.41^{\prime}$ & & & & & & & & 2 & 3 & & 5 & & \\
\hline & Paosha & $33^{\circ} 43^{\prime} 22.22^{\prime}$ & $105^{\circ} 40^{\prime} 41.78^{\prime}$ & & & & & & 3 & & & & 1 & 4 & & \\
\hline & Hongchuan & $33^{\circ} 44^{\prime} 51.41^{\prime}$ & $105^{\circ} 54^{\prime} 14.41^{\prime}$ & & & & 1 & & & 2 & & & & 3 & & \\
\hline & Caofeng & $35^{\circ} 37^{\prime} 19.76^{\prime}$ & $106^{\circ} 50^{\prime} 43.81^{\prime}$ & & & & & & & 5 & 1 & & & 6 & & \\
\hline & Huating & $35^{\circ} 14^{\prime} 8.86^{\prime}$ & $106^{\circ} 37^{\prime} 29.40^{\prime}$ & & 1 & & & & & 1 & 2 & & 1 & 5 & & \\
\hline & Jikou & $34^{\circ} 33^{\prime} 16.76^{\prime}$ & $105^{\circ} 29^{\prime} 25.60^{\prime}$ & & 3 & & & & & 1 & 1 & & & 5 & & \\
\hline & Lixian & $34^{\circ} 10^{\prime} 8.42^{\prime}$ & $104^{\circ} 46^{\prime} 31.82^{\prime}$ & & 2 & & & & & & & & & 2 & & \\
\hline & Xincheng & $35^{\circ} 38^{\prime} 20.54^{\prime}$ & $106^{\circ} 55^{\prime} 32.35^{\prime}$ & & 5 & & & & & 11 & & & & 16 & & \\
\hline & Pingyuan & $35^{\circ} 37^{\prime} 1.79^{\prime}$ & $107^{\circ} 2^{\prime} 5.75^{\prime}$ & & 3 & & & & & 1 & & & 7 & 11 & & \\
\hline \multirow[t]{3}{*}{ Shaanxi } & Yangling & $34^{\circ} 16^{\prime} 18.82^{\prime}$ & $108^{\circ} 6^{\prime} 34.66^{\prime}$ & & & & & & & & & & 3 & 3 & 0 & 10 \\
\hline & Baoji & $34^{\circ} 23^{\prime} 23.90^{\prime}$ & $107^{\circ} 32^{\prime} 13.16^{\prime}$ & & & & & & & & & & 4 & 4 & & \\
\hline & Weinan & $34^{\circ} 47^{\prime} 4.35^{\prime}$ & $109^{\circ} 46^{\prime} 9.36^{\prime}$ & & & & & & & & & & 3 & 3 & & \\
\hline \multirow[t]{17}{*}{ Hebei } & Langfang & $40^{\circ} 00^{\prime} 40.02^{\prime}$ & $116^{\circ} 54^{\prime} 55.44^{\prime}$ & & & & & & & 4 & & & 6 & 10 & 19 & 45 \\
\hline & Longyao & $37^{\circ} 21^{\prime} 15.52^{\prime}$ & $114^{\circ} 48^{\prime} 43.36^{\prime}$ & & & 1 & & & & & & & & 1 & & \\
\hline & Mancheng & $38^{\circ} 56^{\prime} 49.06^{\prime}$ & $115^{\circ} 22^{\prime} 0.30^{\prime}$ & & & 2 & & & & 2 & & & & 4 & & \\
\hline & Renxian & $37^{\circ} 05^{\prime} 55.07^{\prime}$ & $114^{\circ} 41^{\prime} 37.68^{\prime}$ & & & & & & & & & & 2 & 2 & & \\
\hline & Yongnnian & $36^{\circ} 47^{\prime} 18.70^{\prime}$ & $114^{\circ} 31^{\prime} 21.56^{\prime}$ & & & 3 & & & & 4 & & & & 7 & & \\
\hline & Jizhou & $37^{\circ} 34^{\prime} 52.14^{\prime}$ & $115^{\circ} 32^{\prime} 44.27^{\prime}$ & & & 1 & & & & & & & 1 & 2 & & \\
\hline & Gaocheng & $37^{\circ} 59^{\prime} 58.52^{\prime}$ & $114^{\circ} 52^{\prime} 12.26^{\prime}$ & & & 2 & & & & 1 & & & 1 & 4 & & \\
\hline & Quzhou & $36^{\circ} 46^{\prime} 42.28^{\prime}$ & $114^{\circ} 54^{\prime} 55.38^{\prime}$ & & & 1 & & & & 1 & & & & 2 & & \\
\hline & Nangong & $37^{\circ} 21^{\prime} 34.31^{\prime}$ & $115^{\circ} 20^{\prime} 22.11^{\prime}$ & & & 1 & & & & & & & 2 & 3 & & \\
\hline & Tangshan & $39^{\circ} 41^{\prime} 8.37^{\prime}$ & $118^{\circ} 06^{\prime} 51.16^{\prime}$ & & & 1 & & & & 3 & & & & 4 & & \\
\hline & Chengan & $36^{\circ} 26^{\prime} 53.04^{\prime}$ & $114^{\circ} 43^{\prime} 25.85^{\prime}$ & & & 2 & & & & & & & & 2 & & \\
\hline & Xinji & $37^{\circ} 57^{\prime} 6.20^{\prime}$ & $115^{\circ} 15^{\prime} 9.73^{\prime}$ & & & & & & & & & & 3 & 3 & & \\
\hline & Cangxian & $38^{\circ} 12^{\prime} 42.69^{\prime}$ & $117^{\circ} 00^{\prime} 32.20^{\prime}$ & & & 1 & & & & 5 & & & & 6 & & \\
\hline & Gaoyang & $38^{\circ} 41^{\prime} 40.54^{\prime}$ & $115^{\circ} 48^{\prime} 45.78^{\prime}$ & & & & & & & & & & 2 & 2 & & \\
\hline & Wuyi & $37^{\circ} 46^{\prime} 46.97^{\prime}$ & $115^{\circ} 54^{\prime} 4.64^{\prime}$ & & & & & & & 3 & & & 3 & 6 & & \\
\hline & Anxin & $38^{\circ} 56^{\prime} 2.01^{\prime}$ & $115^{\circ} 57^{\prime} 13.48^{\prime}$ & & & 1 & & & & & & & & 1 & & \\
\hline & Qingyuan & $38^{\circ} 46^{\prime} 17.50^{\prime}$ & $115^{\circ} 26^{\prime} 54.28^{\prime}$ & & & 3 & & & & 2 & & & & 5 & & \\
\hline \multirow[t]{3}{*}{ Zhejiang } & Dongyang & $29^{\circ} 17^{\prime} 31.86^{\prime}$ & $120^{\circ} 13^{\prime} 7.61^{\prime}$ & 2 & & & & 1 & & & & & 23 & 26 & 2 & 24 \\
\hline & & & Total & 3 & 38 & 70 & 1 & 1 & 3 & 76 & 63 & 20 & 120 & 395 & 112 & 283 \\
\hline & & & Ratio (\%) & 0.76 & 9.62 & 17.72 & 0.25 & 0.25 & 0.76 & 19.24 & 15.95 & 5.06 & 30.38 & & 28.35 & 71.65 \\
\hline
\end{tabular}




\section{Phylogenetic analysis}

Based on the partial TEF- $1 \alpha$ sequences, a total of 38 haplotypes was obtained. The dominant species identified in this study showed the highest diversity in haplotype: 14 haplotypes for $F$. verticillioides, 8 for $F$. graminearum and 6 for $F$. proliferatum. Low diversity was found in $F$. boothii (2 haplotypes), F. subglutinans (3 haplotypes) and $F$. temperatum (2 haplotypes). A summary of the polymorphism and diversity is presented in Table 4 . The sequences of $F$. verticillioides strains showed the highest value of haplotypic diversity $(0.862)$ indicating the highest level of polymorphism. F. boothii revealed the lowest diversity, the sequences of most isolates (37/38) were the same haplotype as the holotype of the species, the South African strain CBS 316.73/ NRRL26916) and only one SNP was detected between the two haplotypes resulting in a unique new genotype.

Molecular phylogenetic analysis was performed to reveal the evolutionary relationship of the isolates together with several reference strains of FGSC and FFSC and an isolate of $F$. solani as outgroup. Bootstrap analyses clearly classified all haplotypes into two clades coalescing with either FFSC or FGSC. Within each species complex, the haplotypes clustered into different subclades with reference isolates (Figure 2).

\section{Ability of mycotoxin production}

We identified the trichothecene chemotype of isolates within FGSC based on PCR reactions targeted at the Tri3 and Tri12 gene (Ward et al., 2008). All F. graminearum and $F$. boothii isolates were characterised as 15-ADON producers, while the $F$. asiaticum and $F$. meridionale isolates had the NIV chemotype.

To assess the ability of isolates within FFSC to produce fumonisin, the presence of the FUM1 gene was checked by PCR amplification using two different primer sets: Fum-1/
Fum-2 and Fum-3/Fum-4. All of the 120 F. verticillioides isolates were positive with both sets of primers. This indicates that all $F$. verticillioides isolates possess the FUM1 gene and have the potential to produce fumonisins. All $F$. proliferatum $(\mathrm{n}=76)$ and . fujikuroi $(\mathrm{n}=3)$ isolates amplified the expected $420 \mathrm{bp}$ fragment of the FUM1 gene using Fum-1/Fum-2. However, no amplicon was observed using primers Fum-3/Fum-4 due to 1 or more single nucleotide polymorphisms in the primer regions in these species. Finally, all the F. subglutinans and F. temperatum isolates lacked the FUM1 gene and are presumably unable to produce fumonisins.

\section{Mating type determination}

Species in the FFSC are considered heterothallic with strains having one of the two mating types MAT1-1 or MAT1-2. Regardless of the presence of the mating types for some species no sexual stage is known and hence these are presumed asexual. The populations of $F$. verticillioides, F. proliferatum and F. subglutinans all showed both mating type idiomorphs and combining all isolates the proportion of MAT1-1 and MAT1-2 idiomorphs within each species did not significantly differ from equal rations expected for sexual populations ( $\mathrm{Chi}^{2}$-tests, $P=0.23, P=0.09$ and $P=0.31$, respectively) (Supplementary Table S1).

\section{Pathogenicity test}

F. graminearum is a main pathogen of both wheat and maize worldwide. In contrast, F. boothii although phylogenetically related to $F$. graminearum, has never been isolated from wheat. In order to compare their host preference and variation in pathogenicity, we tested the pathogenicity of three populations on wheat and maize stalks: F. graminearum isolates from wheat (Fg-wheat), $F$. graminearum from maize (Fg-maize) and F. boothii from maize (Fb-maize). Fifteen strains were selected randomly from each population. The IIS of Fg-wheat was significantly higher $(P<0.05)$ than Fg-maize, while Fb-maize showed the

Table 4. Global polymorphism of the nucleotide alignments of sequences of TEF-1a gene of Fusarium species including more than 20 isolates.

\begin{tabular}{|c|c|c|c|c|c|c|}
\hline & Species & Sample size & $\begin{array}{l}\text { Number of } \\
\text { segregating } \\
\text { sites }\end{array}$ & $\begin{array}{l}\text { Number of } \\
\text { haplotypes }\end{array}$ & $\begin{array}{l}\text { Number of } \\
\text { parsimony } \\
\text { informative site } \\
\text { between alleles }\end{array}$ & $\begin{array}{l}\text { Haplotypic } \\
\text { diversity }\end{array}$ \\
\hline \multirow[t]{2}{*}{ FGSC } & F. graminearum & 70 & 10 & 8 & 6 & 0.665 \\
\hline & F. boothii & 38 & 1 & 2 & 0 & 0.053 \\
\hline \multirow[t]{4}{*}{ FFSC } & F. verticillioides & 120 & 14 & 14 & 12 & 0.862 \\
\hline & F. proliferatum & 76 & 11 & 6 & 9 & 0.363 \\
\hline & F. subglutinans & 63 & 12 & 3 & 12 & 0.258 \\
\hline & F. temperatum & 20 & 4 & 2 & 4 & 0.479 \\
\hline
\end{tabular}




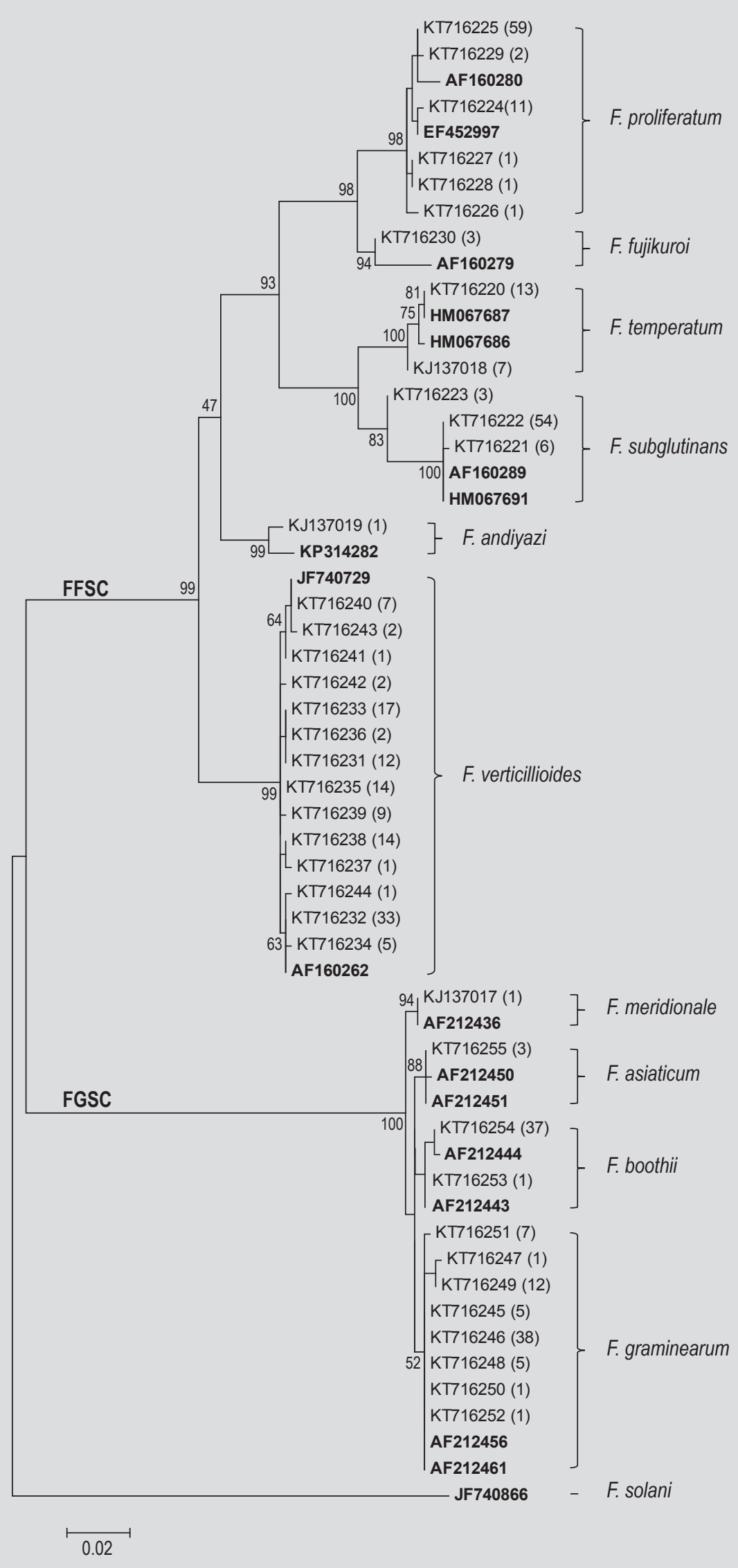

Figure 2. Phylogenetic tree inferred from TEF-1a sequences by maximum likelihood method with program MEGA5.2. The numbers above internodes represent bootstrap support based on 1000 pseudoreplicates. The GenBank accession numbers in bold are reference sequences published previously. 
lowest pathogenicity. This indicated there is difference in the pathogenicity towards wheat between isolates collected from wheat and maize even if they belong to the same species.

In the pathogenicity assays on maize no specialisation was observed Although Fb-maize and Fg-wheat populations showed the largest and smallest average lesion length on maize stalks respectively, no significant difference $(P=0.75)$ was observed between the three populations (Table 5). Isolates within a single population can vary considerably from one another (Figure 3).

\section{Discussion}

FER is a devastating disease of maize all over the world, where mycotoxin accumulation depends on the etiological agents. Particularly in China, FER forms an important constraint on maize production. To take the appropriate agronomic measures, population dynamic studies on the pathogens are essential. Therefore, investigating the Fusarium species and their mycotoxins associated with FER in maize is indispensable for sustainable agriculture in China. There have been a few reports focusing on particular regions in China (Ndoye et al., 2012; Qiu et al., 2015; Zhang et al., 2013b). Recently, Fu et al. (2015) investigated the Fusarium species associated with maize kernels from nine provinces in China based on a large collection $(n=2,321)$. Their study focused on the natural occurrence of Fusarium on maize including non-pathogenic species and latent infections with Fusarium. These researchers collected maize ears at random and no visible signs of mould contamination were observed in most of them. Here, we focused on the pathogen of Fusarium ear rot and all sampled ears showed clear symptoms of FER with pink or white spore masses. Only one isolate from each maize cob after single-spore

Table 5. The incidence of infected spikelets on wheat and lesion length on maize stalks of three population.

\begin{tabular}{lll} 
Population $^{1}$ & Means of IIS & $\begin{array}{l}\text { Means of lesion } \\
\text { length }(\mathbf{c m})^{3}\end{array}$ \\
Fb-maize & $25.39 \mathrm{c}$ & $6.99 \mathrm{a}$ \\
Fg-maize & $33.82 \mathrm{~b}$ & $6.81 \mathrm{a}$ \\
Fg-wheat & $38.42 \mathrm{a}$ & $6.69 \mathrm{a}$ \\
\hline
\end{tabular}

${ }^{1} \mathrm{Fb}$-maize and Fg-maize are Fusarium boothii and Fusarium graminearum isolates from maize, Fg-wheat are Fusarium graminearum isolates from wheat.

2 IIS is the incidence of infected spikelets. For statistical analysis, IIS data were arcsine transformed.

${ }^{3}$ ANOVA analysis has been performed with Duncan's multiple range test as post-hoc test and values within a column followed by different letters are significantly different at $P<0.05$.

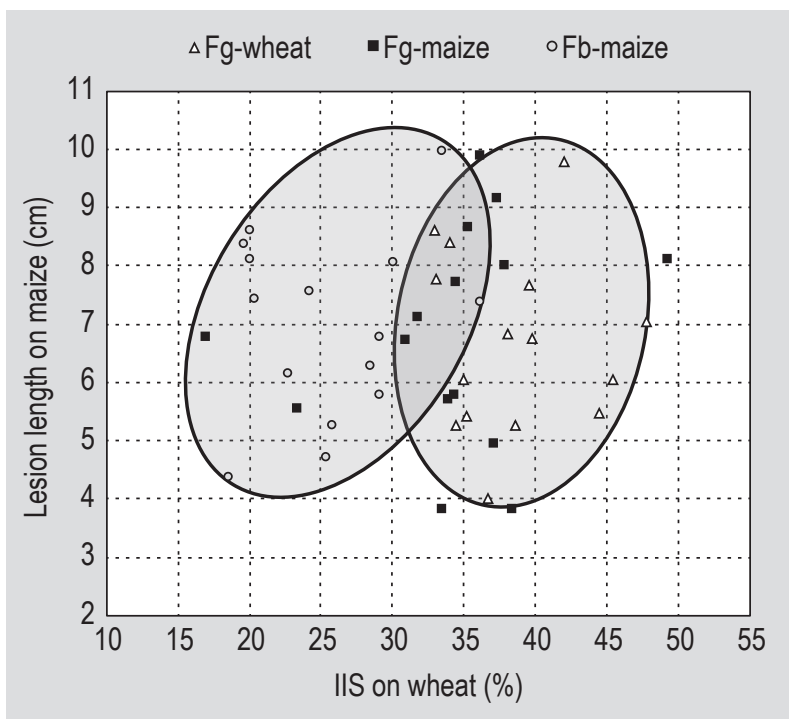

Figure 3. Pathogenicity of Fusarium graminearum strains isolated from wheat ( $\mathrm{Fg}$-wheat, triangles), $F$. graminearum strains isolated from maize (Fg-maize, diamonds) and Fusarium boothii strains isolated from maize (Fb-maize, circles) on wheat (as incidence of infected spikelets; IIS) and on maize (as length of lesions in maize stalks).

isolation was preserved, preventing re-isolation of the same isolate. Because of differences in the experimental approach, distinctly different species profiles may be expected between the two studies. Fu et al. identified nine Fusarium species from non-symptomatic ears. Six of them were also found in this study, indicating that these species are capable of infecting maize latently, but they can also cause disease under conducive conditions. In both studies $F$. verticillioides and $F$. graminearum were the predominant species. However, we also found F. proliferatum (19.24\%) and F. subglutinans (15.95\%) to be frequently associated with FER, which occurred only sporadically on seemingly healthy maize ears (Fu et al., 2015). F. boothii - absent in Fu's study done in 2012 - was isolated in three provinces with an overall proportion of $9.62 \%$. This may indicate that $F$. boothii infects maize with a short latent period before symptoms occur or became much more prevalent in recent years.

In total, we identified ten Fusarium species in the main maize producing areas in China. F. verticillioides is the dominant species that occurred in all provinces. This is in agreement with previous studies in eastern China (Qiu et al., 2015; Zhang et al., 2013b). F. verticillioides is also the most commonly isolated fungus from maize across the world (Aguin et al., 2014; Madania et al., 2013; Torres et al., 2001), while also F. proliferatum and $F$. subglutinans are commonly associated with FER. We observed a similar trend in China, where the ratio of $F$. subglutinans to $F$. proliferatum proved highest in Heilongjiang and Jilin in the most northern and coldest region in China, while in the more southern provinces Gansu and Hebei, no $F$. 
subglutinans was isolated. These results support the notice that $F$. subglutinans prefers a cooler temperature (Boutigny et al., 2012; Goertz et al., 2010; Logrieco et al., 2002).

F. temperatum is a newly recorded species found first in 2011 in Belgium (Scauflaire et al., 2011). Recently, it was reported in many countries, including Spain (Varela et al., 2013), Poland (Czembor et al., 2014), Argentina (Fumero et al., 2015), and Korea (Shin et al., 2014). In China, $F$. temperatum was first reported in Guizhou and Hubei Province (Wang et al., 2014), and even more recent in Sichuan and Yunnan (Fu et al., 2015). These are all mountain regions with a warm climate. Previous reports suggested that $F$. temperatum prefers warmer regions compared to F. subglutinans (Fumero et al., 2015; Moretti et al., 2008; Scauflaire et al., 2011). However, in this study, we also collected $F$. temperatum in Jilin, northern China, where the annual average temperatures are $3 \sim 5{ }^{\circ} \mathrm{C}$ and to our knowledge this is the coldest region where $F$. temperatum was isolated so far. F. temperatum co-occurred with its sister species $F$. subglutinans.

F. graminearum is another of the dominant species on maize ears worldwide (Boutigny et al., 2014; Lee et al., 2012). In our collection, $17.7 \%$ of the isolates were identified as $F$. graminearum, slightly less than the incidence of $F$. proliferatum. This is in agreement with previous studies for northern China (Ndoye et al., 2012) but distinct from what was reported for northeast China (Ndoye et al., 2012). Based on PCR diagnostics, Ndoye et al. identified $70 \%$ of the isolates collected in the northeast of China as F. asiaticum, while $30 \%$ of the isolates were identified as F. graminearum. In this study, most isolates within FGSC in the Northeast were $F$. graminearum ( $\mathrm{n}=51,70 \%)$, followed by $21 \mathrm{~F}$. boothii (29\%) and only one F. asiaticum (1\%) was identified.

F. boothii was identified in both northwest and northeast of China. This species has not been found on maize in China in previous reports maybe due to the detection methods (Ndoye et al., 2012; Qiu and Shi, 2014; Qiu et al., 2015). F. boothii has been identified in many countries including Ethiopia (O'Donnell et al., 2008), Argentina (Sampietro et al., 2010), Kenya (Wagacha et al., 2010), South Africa (Boutigny et al., 2011), Nepal (Desjardins and Proctor, 2011), Mexico (Malihipour et al., 2012), and Korea (Lee et al., 2012). All of these regions are warm compared to the northeast of China. This indicates that $F$. boothii not only occurs in warm regions, but is capable to survive even $-30{ }^{\circ} \mathrm{C}$ in winter.

Climate is usually thought to be an important driver of species distribution. In Asia, temperature is frequently used to explain $F$. graminearum as the predominant species of FGSC in northern areas, while $F$. asiaticum dominates southern areas (Qu et al., 2008; Suga et al., 2008). However, our previous study did not corroborate this finding. In contrast, a strong association between crops and pathogen species was observed: F. asiaticum dominated in rice-wheat rotation areas while $F$. graminearum is linked to maizewheat rotation (Zhang et al., 2012). Similar relations to hostpreference were observed in the USA (Gale et al., 2011), South Korea (Lee et al., 2012) and Brazil (Gomes et al., 2015). Also increased production of maize and/or climatic changes may have resulted in the shift from F. culmorum to F. graminearum in the Netherlands (Waalwijk et al., 2003). F. boothii has a strong association with maize and ear rot. However, it has rarely been found on wheat, with only small populations in Ethiopia ( $\mathrm{n}=9,29 \%$ ) (O'Donnell et al., 2008) and Mexico (n=7, 47\%) (Malihipour et al., 2012). Many reports on the Fusarium composition on wheat and barley are available for China, yet $F$. boothii has never been retrieved (Qiu and Shi, 2014; Yang et al., 2008; Zhang et al., 2010, 2013a). In this study, F. boothii was found widely distributed in both northwest and northeast China including 12 sampling sites (Table 3 ). Approximately half of them were isolated in the provinces Heilongjiang and Jilin, where farmers only grow maize every year. The other $F$. boothii strains were collected from the central and south parts in Gansu. In this area, wheat-maize rotation was customary, but in the most recent decade, the acreage of wheat has decreased sharply and maize became the dominant crop (data from China's National Bureau of Statistics). No F. boothii strains were found in Hebei and Shaanxi, where the traditional wheat-maize rotation in one year is customary. Based on this, we propose that $F$. boothii may have maize as preferred host and wheat, which is rotated with maize, restricts its infection cycle. Similar conditions are encountered in South Korea (Lee et al., 2012), where farmers only grow maize and $F$. boothii was commonly detected. It is also interesting that all FGSC isolates $(\mathrm{n}=17)$ in Gansu were F. boothii and no F. graminearum was found. This is reminiscent to the situation in South Africa where a large and unique $F$. boothii population is associated with FER (Boutigny et al., 2011). The cropping system is also similar between Gansu and South Africa, occasionally barley or wheat are rotated with maize over multiple years. In this cropping system, maize is grown continuously if we consider a regional scale, so $F$. boothii can complete all parts of its life cycle on maize. But in Hebei, wheat-maize rotation is strict for two harvests per year. In the wheat season maize is absent in this large region. If wheat is an essential part of the life cycle, $F$. boothii will have to compete with F. graminearum on wheat. Alternatively, F. boothii may be growing solely on maize and survive on crop debris or in soil during the wheat cultivation. This may result in a small population that is difficult to detect due to its size.

To validate if differentiation in host-specific pathogenicity influences the distribution of $F$. boothii, we tested the pathogenicity of three populations on wheat and maize stalk respectively: F. graminearum isolates from wheat (Fg-wheat), F. graminearum from maize (Fg-maize) and $F$. 
boothii from maize (Fb-maize). These populations showed significant differences in pathogenicity on wheat with the Fg-wheat population as the most aggressive, followed by the Fg-maize population and the Fb-maize being the least pathogenic. This result is in agreement with a previous report in Mexico (Malihipour et al., 2012). Remarkably, in pathogenicity on maize no significant differences were found among these three populations. The toothpick inoculation procedure used to test the pathogenicity on maize stalks may not directly reflect the ability of this species to cause FER. In field conditions, maize ear rot and stalk rot often coincide (Bottalico, 1998; Picot et al., 2012). Stalk rot is easy to score by lesion length and artificial inoculation on maize cobs may not be a good representation for the natural route of infection.

F. boothii showed extremely low haplotypic diversity of $T E F-1 \alpha$ gene. Only two haplotypes were found and most isolates $(37 / 38)$ were fixed for one. This indicates that the structure of $F$. boothii populations is much more clonal than that of the other encountered species. We hypothesise that this may represent either a new migrant population with limited genetic variation or an asexually propagating population under a strong selective pressure. Both options may apply for $F$. boothii and more research is required to provide conclusive answers.

In this study only one strain of $F$. meridionale was isolated $(0.25 \%)$, originating from Hongchuan on the border between Gansu and Sichuan Province. F. meridionale was reported in Sichuan, Yunnan and Hubei on wheat and barley, but similar to our study, it was typically found at low frequencies (Wang et al., 2010; Yang et al., 2008; Zhang et al., 2012). This contrasts with reports where $F$. meridionale was the predominant species on maize in Nepal and Northern Argentina (Desjardins and Proctor, 2011; Sampietro et al., 2012). However, small populations of $F$. meridionale were also reported in Brazil (1.1\%), Korea (1.2\%) and South Africa (3.6\%) (wheat 3.6\%, maize roots 14\%). It seems that F. meridionale is preferentially found on maize, but may be affected by other factors. Recently, a larger F. meridionale population was identified on wheat in Brazil thought to be related to the two harvests of maize in one year (Del Ponte et al., 2015). We also found all the sites where F. meridionale were reported are mountain regions.

Species within FGSC typically produce type B trichothecenes and different chemotypes may affect species or population ecology, because the corresponding mycotoxins differ in toxicity and bioactivity (Kimura et al., 1998). Our previous study also indicated that chemotype differences have a significant impact on pathogen fitness (Zhang et al., 2012). Recently a number of displacement events appear to find their origin in the inadvertent introduction of new genotypes into new regions: 3-ADON F. graminearum in Canada (Ward et al., 2008); 3-ADON F. asiaticum in Eastern
China (Zhang et al., 2012); 15-ADON F. graminearum in Uruguay (Umpierrez-Failache et al., 2013); and NIVproducing F. asiaticum in the southern United States (Gale et al., 2011). These genotypes appear to have selective advantages and recently overcame significant barriers due to changes in agricultural practices or environmental conditions. In this study, all F. graminearum isolates on maize had the 15-ADON chemotype, which is in agreement with previous reports (Ndoye et al., 2012; Qiu and Shi, 2014). In addition to this, another $15-\mathrm{ADON}$ producing species, F. boothii, was identified and the occurrence of this species may increase with the expansion of maize cultivation in China. In our study, only four NIV producers (three F. asiaticum and one F. meridionale) were found. This is in contrast to Ndoye' study, where $70 \%$ of the isolates in northeast China in 2009 were NIV producers (F. asiaticum). This change may reflect a regional difference or a chemotype/species shift in recent years. Similar results were reported from Switzerland, where both dimensional and temporal variation of Fusarium composition on maize was observed (Dorn et al., 2009, 2011). Temporal variation events were also reported on wheat (Waalwijk et al., 2003; Ward et al., 2008). This study was performed on a collection from a single sampling year. Therefore, continuous sampling is needed to distinguish potential trends.

Members of the FFSC are capable of producing fumonisins and the main producers are $F$. verticillioides and $F$. proliferatum. Several other FFSC members also harbour the entire fumonisin gene cluster involved in the biosynthesis of this secondary metabolite and some were shown to produce varying amounts of fumonisins (Proctor et al., 2013). A PCR assay with two sets of primers revealed that all F. verticillioides possessed the FUM1 gene. This result is concordant with other studies that established $F$. verticillioides as a potent fumonisin producer (Proctor et al., 2006). Also F. proliferatum and F. fujikuroi are fumonisin producers and F. andiyazi was shown to produce only trace amounts of fumonisin (Leslie et al., 2005). F. subglutinans is considered to be a fumonisin non-producing species (Nelson et al., 1992) due to the absence of the cluster of fumonisin biosynthetic genes (FUM cluster) (Proctor et al., 2004). We found all F. subglutinans were negative for both primer sets. It is controversial whether F. temperatum is a fumonisin producer. In Belgium, Scauflaire et al. (2012) found that one out of eleven isolates produced low levels of $\mathrm{FB}_{1}$. In Argentina, higher ratio of F. temperatum isolates $(10 / 38)$ were identified as low fumonisin producers (max. $130 \mu \mathrm{g} / \mathrm{g}$ ) in comparison with the main fumonisin producers (Fumero et al., 2015). However, all ten F. temperatum strains isolated in southern China were able to produce both $\mathrm{FB}_{1}$ and $\mathrm{FB}_{2}$ (Wang et al., 2014). In the present study, twenty $F$. temperatum strains were all negative to two sets of primers, indicating the possible absence of the FUM1 gene. However, inconsistencies between PCR and LC-MS assay had also been reported (Covarelli et al., 2012). This may reflect 
mutations of the FUM cluster or alteration(s) in the control of FUM gene expression.

Although many reports on occurrence and prevalence of Fusarium species exist (reviewed by Van der Lee et al., 2015) and population structures are found to be changing over time, the drivers for this phenomenon are still largely unknown. Both climate and cropping systems have been suggested to play an important role, but comparative biological studies are scarce. However, based on our findings and data from literature we conclude that a cropping system with wheat/maize rotation selects for F. graminearum, while a wheat/rice rotation selects for $F$. asiaticum. In contrast, $F$. boothii is selected when maize is cultivated without rotation. The pathogens in wheat and barley crops are predominantly F. graminearum as well as F. asiaticum. When maize is grown under colder climatological conditions in China, a higher occurrence of $F$. temperatum is observed while $F$. meridionale seems restricted to mountain areas. Each of these species has their characteristic mycotoxin profile, thus, if we can predict which species will be prevalent, then we also can predict the resulting mycotoxin contamination.

\section{Supplementary material}

Supplementary material can be found online at http:// dx.doi.org/10.3920/WMJ2015.2004.

Table S1. The distribution of different mating type idiomorphs of Fusarium verticillioides, Fusarium proliferatum and Fusarium subglutinans.

\section{Acknowledgements}

This work was supported by a project the Sino-Dutch Joint Scientific Thematic Research Programme (JSTP) [grant numbers 833.13.006 (NL) and 2013DFG31930 (CN) respectively] and the National Natural Science Foundation (No.31201477) (CN) and the Special Fund for Agroscientific Research in the Public Interest (201303016) (CN).

\section{References}

Adejumo, T.O., Hettwer, U. and Karlovsky, P., 2007. Occurrence of Fusarium species and trichothecenes in Nigerian maize. International Journal of Food Microbiology 116: 350-357.

Aguin, O., Cao, A., Pintos, C., Santiago, R., Mansilla, P. and Butron, A., 2014. Occurrence of Fusarium species in maize kernels grown in northwestern Spain. Plant Pathology 63: 946-951.

Baird, R., Abbas, H.K., Windham, G., Williams, P., Baird, S., Ma, P., Kelley, R., Hawkins, L. and Scruggs, M., 2008. Identification of select fumonisin forming Fusarium species using PCR applications of the polyketide synthase gene and its relationship to fumonisin production in vitro. International Journal of Molecular Science 9: 554-570.
Bluhm, B.H., Flaherty, J.E., Cousin, M.A. and Woloshuk, C.P., 2002. Multiplex polymerase chain reaction assay for the differential detection of trichothecene- and fumonisin-producing species of Fusarium in cornmeal. Journal of Food Protection 65: 1955-1961. Bottalico, A., 1998. Fusarium disease of cereals: species complex and related mycotoxin profiles, in Europe. Journal of Plant Pathology 80: 85-103.

Boutigny, A.-L., Ward, T.J., Coller, G.J.V., Flett, B., Lamprecht, S.C., O'Donnell, K. and Viljoen, A., 2011. Analysis of the Fusarium graminearum species complex from wheat, barley and maize in South Africa provides evidence of species-specific differences in host preference. Fungal Genetics and Biology 48: 914-920.

Boutigny, A.L., Beukes, I., Small, I., Zuhlke, S., Spiteller, M., Van Rensburg, B.J., Flett, B. and Viljoen, A., 2012. Quantitative detection of Fusarium pathogens and their mycotoxins in South African maize. Plant Pathology 61: 522-531.

Boutigny, A.L., Ward, T.J., Ballois, N., Iancu, G. and Ioos, R., 2014. Diversity of the Fusarium graminearum species complex on French cereals. European Journal of Plant Pathology 138: 133-148.

Chen, C.J., Yu, J.J., Bi, C.W., Zhang, Y.N., Xu, J.Q., Wang, J.X. and Zhou, M.G., 2009. Mutations in a $\beta$-tubulin confer resistance of Gibberella zeae to Benzimidazole fungicides. Phytopathology 99: 1403-1411. Covarelli, L., Stifano, S., Beccari, G., Raggi, L., Lattanzio, V.M.T. and Albertini, E., 2012. Characterization of Fusarium verticillioides strains isolated from maize in Italy: Fumonisin production, pathogenicity and genetic variability. Food Microbiology 31: 17-24.

Czembor, E., Stepien, L. and Waskiewicz, A., 2014. Fusarium temperatum as a new species causing ear rot on maize in Poland. Plant Disease 98: 1001.

Del Ponte, E.M., Spolti, P., Ward, T.J., Gomes, L.B., Nicolli, C.P., Kuhnem, P.R., Silva, C.N. and Tessmann, D.J., 2015. Regional and field-specific factors affect the composition of Fusarium head blight pathogens in subtropical no-till wheat agroecosystem of Brazil. Phytopathology 105: 246-254.

Desjardins, A.E. and Proctor, R.H., 2011. Genetic diversity and trichothecene chemotypes of the Fusarium graminearum clade isolated from maize in Nepal and identification of a putative new lineage. Fungal Genetics and Biology 115: 38-48.

Dorn, B., Forrer, H.R., Jenny, E., Wettstein, F.E., Bucheli, T.D. and Vogelgsang, S., 2011. Fusarium species complex and mycotoxins in grain maize from maize hybrid trials and from grower's fields. Journal of Applied Microbiology 111: 693-706.

Dorn, B., Forrer, H.R., Schurch, S. and Vogelgsang, S., 2009. Fusarium species complex on maize in Switzerland: occurrence, prevalence, impact and mycotoxins in commercial hybrids under natural infection. European Journal of Plant Pathology 125: 51-61.

Fu, M., Li, R.J., Guo, C.C., Pang, M.H., Liu, Y.C. and Dong, J.G., 2015. Natural incidence of Fusarium species and fumonisins B-1 and B-2 associated with maize kernels from nine provinces in China in 2012. Food Additives and Contaminants Part A 32: 503-511.

Fumero, M., Reynoso, M. and Chulze, S., 2015. Fusarium temperatum and Fusarium subglutinans isolated from maize in Argentina. International Journal of Food Microbiology 199: 86-92. 
Gale, L.R., Harrison, S.A., Ward, T.J., O’Donnell, K., Milus, E.A., Gale, S.W. and Kistler, H.C., 2011. Nivalenol-type populations of Fusarium graminearum and F. asiaticum are prevalent on wheat in southern Louisiana. Phytopathology 101: 124-134.

Geiser, D.M., Aoki, T., Bacon, C.W., Baker, S.E., Bhattacharyya, M.K., Brandt, M.E., Brown, D.W., Burgess, L.W., Chulze, S., Coleman, J.J., Correll, J.C., Covert, S.F., Crous, P.W., Cuomo, C.A., De Hoog, G.S., Di Pietro, A., Elmer, W.H., Epstein, L., Frandsen, R.J., Freeman, S., Gagkaeva, T., Glenn, A.E., Gordon, T.R., Gregory, N.F., HammondKosack, K.E., Hanson, L.E., Jimenez-Gasco Mdel, M., Kang, S., Kistler, H.C., Kuldau, G.A., Leslie, J.F., Logrieco, A., Lu, G., Lysoe, E., Ma, L.J., McCormick, S.P., Migheli, Q., Moretti, A., Munaut, F., O’Donnell, K., Pfenning, L., Ploetz, R.C., Proctor, R.H., Rehner, S.A., Robert, V.A., Rooney, A.P., Bin Salleh, B., Scandiani, M.M., Scauflaire, J., Short, D.P., Steenkamp, E., Suga, H., Summerell, B.A., Sutton, D.A., Thrane, U., Trail, F., Van Diepeningen, A., Vanetten, H.D., Viljoen, A., Waalwijk, C., Ward, T.J., Wingfield, M.J., Xu, J.R., Yang, X.B., Yli-Mattila, T. and Zhang, N., 2013. One fungus, one name: defining the genus Fusarium in a scientifically robust way that preserves longstanding use. Phytopathology 103: 400-408.

Gelderblom, W.C.A., Jaskiewicz, K., Marasas, W.F.O., Thiel, P.G., Horak, R.M., Vleggaar, R. and Kriek, N.P.J., 1988. Fumonisins novel mycotoxins with cancer-promoting activity produced by Fusarium moniliforme. Applied and Environmental Microbiology 54: 1806-1811.

Goertz, A., Zuehlke, S., Spiteller, M., Steiner, U., Dehne, H.W., Waalwijk, C., De Vries, I. and Oerke, E.C., 2010. Fusarium species and mycotoxin profiles on commercial maize hybrids in Germany. European Journal of Plant Pathology 128: 101-111.

Gomes, L.B., Ward, T.J., Badiale-Furlong, E. and Del Ponte, E.M., 2015. Species composition, toxigenic potential and pathogenicity of Fusarium graminearum species complex isolates from southern Brazilian rice. Plant Pathology 64: 980-987.

Kimura, M., Kaneko, I., Komiyama, M., Takatsuki, A., Koshino, H., Yoneyama, K. and Yamaguchi, I., 1998. Trichothecene 3-O-acetyltransferase protects both the producing organism and transformed yeast from related mycotoxins. Cloning and characterization of Tri101. Journal of Biological Chemistry 273: 1654-1661.

Kvas, M., Marasas, W.F.O., Wingfield, B.D., Wingfield, M.J. and Steenkamp, E.T., 2009. Diversity and evolution of Fusarium species in the Gibberella fujikuroi complex. Fungal Diversity 34: 1-21.

Lee, J., Kim, H., Jeon, J.J., Kim, H.S., Zeller, K.A., Carter, L.L., Leslie, J.F. and Lee, Y.W., 2012. Population structure of and mycotoxin production by Fusarium graminearum from maize in South Korea. Applied and Environmental Microbiology 78: 2161-2167.

Leslie, J.F., Zeller, K.A., Lamprecht, S.C., Rheeder, J.P. and Marasas, W.F.O., 2005. Toxicity, pathogenicity, and genetic differentiation of five species of Fusarium from Sorghum and Millet. Phytopathology 95: 275-283.

Librado, P. and Rozas, J., 2009. DnaSP v5: a software for comprehensive analysis of DNA polymorphism data. Bioinformatics 25: 1451-1452.

Logrieco, A., Mule, G., Moretti, A. and Bottalico, A., 2002. Toxigenic Fusarium species and mycotoxins associated with maize ear rot in Europe. European Journal of Plant Pathology 108: 597-609.
Madania, A., Altawil, M., Naffaa, W., Volker, P.H. and Hawat, M., 2013. Morphological and molecular characterization of Fusarium isolated from maize in Syria. Journal of Phytopathology 161: 452-458.

Malihipour, A., Gilbert, J., Piercey-Normore, M. and Cloutier, S., 2012. Molecular phylogenetic analysis, trichothecene chemotype patterns, and variation in aggressiveness of Fusarium isolates causing head blight in wheat. Plant Disease 96: 1016-1025.

Marasas, W.F.O., 2001. Discovery and occurrence of the fumonisins: a historical perspective. Environmental Health Perspectives 109: 239-243.

Marasas, W.F.O., Riley, R.T., Hendricks, K.A., Stevens, V.L., Sadler, T.W., Gelineau-van Waes, J., Missmer, S.A., Cabrera, J., Torres, O., Gelderblom, W.C.A., Allegood, J., Martinez, C., Maddox, J., Miller, J.D., Starr, L., Sullards, M.C., Roman, A.V., Voss, K.A., Wang, E. and Merrill, A.H., 2004. Fumonisins disrupt sphingolipid metabolism, folate transport, and neural tube development in embryo culture and in vivo: a potential risk factor for human neural tube defects among populations consuming fumonisin-contaminated maize. Journal of Nutrition 134: 711-716.

Miller J.D., Greenhalgh R., Wang Y.Z. and Lu M., 1991. Trichothecene chemotypes of three Fusarium species. Mycologia 83: 121-130.

Moretti, A., Mule, G., Ritieni, A., Laday, M., Stubnya, V., Hornok, L. and Logrieco, A., 2008. Cryptic subspecies and beauvericin production by Fusarium subglutinans from Europe. International Journal of Food Microbiology 127: 312-315.

Ndoye, M., Zhang, J.B., Wang, J.H., Gong, A.D., Li, H.P., Qu, B., Li, S.J. and Liao, Y.C., 2012. Nivalenol and 15-acetyldeoxynivalenol Chemotypes of Fusarium graminearum clade species are prevalent on maize throughout China. Journal of Phytopathology 160: 519-524.

Nelson, P.E., Plattner, R.D., Shackelford, D.D. and Desjardins, A.E., 1992. Fumonisin-B1 production by Fusarium species other than $F$. moniliforme in section Liseola and by some related species. Applied and Environmental Microbiology 58: 984-989.

O’Donnell, K., Ward, T.J., Aberra, D., Kistler, H.C., Aoki, T., Orwig, N., Kimura, M., Bjornstad, S. and Klemsdal, S.S., 2008. Multilocus genotyping and molecular phylogenetics resolve a novel head blight pathogen within the Fusarium graminearum species complex from Ethiopia. Fungal Genetics and Biology 45: 1514-1522.

Picot, A., Hourcade-Marcolla, D., Barreau, C., Pinson-Gadais, L., Caron, D., Richard-Forget, F. and Lannou, C., 2012. Interactions between Fusarium verticillioides and Fusarium graminearum in maize ears and consequences for fungal development and mycotoxin accumulation. Plant Pathology 61: 140-151.

Proctor, R.H., Plattner, R.D., Brown, D.W., Seo, J.A. and Lee, Y.W., 2004. Discontinuous distribution of fumonisin biosynthetic genes in the Gibberella fujikuroi species complex. Mycological Research 108: 815-822.

Proctor, R.H., Plattner, R.D., Desjardins, A.E., Busman, M. and Butchko, R.A.E., 2006. Fumonisin production in the maize pathogen Fusarium verticillioides: Genetic basis of naturally occurring chemical variation. Journal of Agricultural and Food Chemistry 54: 2424-2430.

Proctor, R.H., Van Hove, F., Susca, A., Stea, G., Busman, M., Van der Lee, T., Waalwijk, C., Moretti, A. and Ward, T.J., 2013. Birth, death and horizontal transfer of the fumonisin biosynthetic gene cluster during the evolutionary diversification of Fusarium. Molecular Microbiology 90: 290-306. 
Qiu, J. and Shi, J., 2014. Genetic relationships, carbendazim sensitivity and mycotoxin production of the Fusarium graminearum populations from maize, wheat and rice in eastern China. Toxins 6: 2291-2309.

Qiu, J.B., Xu, J.H., Dong, F., Yin, X.C. and Shi, J.R., 2015. Isolation and characterization of Fusarium verticillioides from maize in eastern China. European Journal of Plant Pathology 142: 791-800.

Qu, B., Li, H.P., Zhang, J.B., Xu, Y.B., Huang, T., Wu, A.B., Zhao, C.S., Carter, J., Nicholson, P. and Liao, Y.C., 2008. Geographic distribution and genetic diversity of Fusarium graminearum and F. asiaticum on wheat spikes throughout China. Plant Pathology 57: 15-24.

Sampietro, D.A., Diaz, C.G., Gonzalez, V., Vattuone, M.A., Ploper, L.D., Catalan, C.A. and Ward, T.J., 2011. Species diversity and toxigenic potential of Fusarium graminearum complex isolates from maize fields in northwest Argentina. International Journal of Food Microbiology 145: 359-364.

Sampietro, D.A., Ficoseco, M.E., Jimenez, C.M., Vattuone, M.A. and Catalan, C.A., 2012. Trichothecene genotypes and chemotypes in Fusarium graminearum complex strains isolated from maize fields of northwest Argentina. International Journal of Food Microbiology 153: 229-233.

Sampietro, D.A., Marin, P., Iglesias, J., Presello, D.A., Vattuone, M.A., Catalan, C.A. and Gonzalez Jaen, M.T., 2010. A molecular based strategy for rapid diagnosis of toxigenic Fusarium species associated to cereal grains from Argentina. Fungal Biology 114: 74-81.

Scauflaire, J., Gourgue, M., Callebaut, A. and Munaut, F., 2012. Fusarium temperatum, a mycotoxin-producing pathogen of maize. European Journal of Plant Pathology 133: 911-922.

Scauflaire, J., Gourgue, M. and Munaut, F., 2011. Fusarium temperatum sp. nov. from maize, an emergent species closely related to Fusarium subglutinans. Mycologia 103: 586-597.

Shin, J.H., Han, J.H., Lee, J.K. and Kim, K.S., 2014. Characterization of the maize stalk rot pathogens Fusarium subglutinans and $F$. temperatum and the effect of fungicides on their mycelial growth and colony formation. Plant Pathology Journal 30: 397-406.

Somma, S., Petruzzella, A.L., Logrieco, A.F., Meca, G., Cacciola, O.S. and Moretti, A., 2014. Phylogenetic analyses of Fusarium graminearum strains from cereals in Italy, and characterisation of their molecular and chemical chemotypes. Crop and Pasture Science 65: 52-60.

Steenkamp, E.T., Wingfield, B.D., Coutinho, T.A., Zeller, K.A., Wingfield, M.J., Marasas, W.F. and Leslie, J.F., 2000. PCR-based identification of MAT-1 and MAT-2 in the Gibberella fujikuroi species complex. Applied and Environmental Microbiology 66: 4378-4382.

Suga, H., Karugia, G.W., Ward, T., Gale, L.R., Tomimura, K., Nakajima, T., Miyasaka, A., Koizumi, S., Kageyama, K. and Hyakumachi, M., 2008. Molecular characterization of the Fusarium graminearum species complex in Japan. Phytopathology 98: 159-166.

Tamura, K., Peterson, D., Peterson, N., Stecher, G., Nei, M. and Kumar, S., 2011. MEGA5: molecular evolutionary genetics analysis using maximum likelihood, evolutionary distance, and maximum parsimony methods. Molecular Biology and Evolution 28: 2731-2739.
Torres, A., Reynoso, M.M., Rojo, F., Ramírez, M.L. and Chulze, S., 2001. Fungal and mycotoxin contamination in home grown maize harvested in the north area of Argentina. Food Additives and Contaminants 18: 836-843.

Ueno, Y., Nakajima, M., Sakai, K., Ishii, K. and Sato, N., 1973. Comparative toxicology of trichothec mycotoxins: inhibition of protein synthesis in animal cells. Journal of Biochemistry 74: 285-296.

Umpierrez-Failache, M., Garmendia, G., Pereyra, S., RodriguezHaralambides, A., Ward, T.J. and Vero, S., 2013. Regional differences in species composition and toxigenic potential among Fusarium head blight isolates from Uruguay indicate a risk of nivalenol contamination in new wheat production areas. International Journal of Food Microbiology 166: 135-140.

Van der Lee, T., Zhang, H., Van Diepeningen, A. and Waalwijk, C., 2015. Biogeography of Fusarium graminearum species complex and chemotypes: a review. Food Additives and Contaminants Part A 32: 453-463.

Varela, C.P., Casal, O.A., Padin, M.C., Martinez, V.F., Oses, M.J.S., Scauflaire, J., Munaut, F., Castro, M.J.B. and Vazquez, J.P.M., 2013. First report of Fusarium temperatum causing seedling blight and stalk rot on maize in Spain. Plant Disease 97: 1252-1253.

Waalwijk, C., Kastelein, P., Vries, I., Kerenyi, Z., Van der Lee, T., Hesselink, T., Kohl, J. and Kema, G., 2003. Major changes in Fusarium spp. in wheat in the Netherlands. European Journal of Plant Pathology 109: 743-754.

Wagacha, J.M., Steiner, U., Dehne, H.W., Zuehlke, S., Spiteller, M., Muthomi, J. and Oerke, E.C., 2010. Diversity in mycotoxins and fungal species infecting wheat in Nakuru District, Kenya. Journal of Phytopathology 158: 527-535.

Wang, J.H., Zhang, J.B., Li, H.P., Gong, A.D., Xue, S., Agboola, R.S. and Liao, Y.C., 2014. Molecular identification, mycotoxin production and comparative pathogenicity of Fusarium temperatum isolated from maize in China. Journal of Phytopathology 162: 147-157.

Wang, X., Cui, Y., Fan, F., Song, Y., Ren, J., Meng, Q., Xu, W. and Jiang, L., 2010. Phylogenetic, carbendazim sensitivity and mycotoxin genotype analyses of Fusarium graminearum complex species isolated from wheat Fusarium head blight in China. Journal of Phytopathology 158: 576-578.

Ward, T.J., Clear, R.M., Rooney, A.P., O’Donnell, K., Gaba, D., Patrick, S., Starkey, D.E., Gilbert, J., Geiser, D.M. and Nowicki, T.W., 2008. An adaptive evolutionary shift in Fusarium head blight pathogen populations is driving the rapid spread of more toxigenic Fusarium graminearum in North America. Fungal Genetics and Biology 45: 473-484

Yang, L., Van der Lee, T., Yang, X., Yu, D. and Waalwijk, C., 2008. Fusarium populations on Chinese barley show a dramatic gradient in mycotoxin profiles. Phytopathology 98: 719-727.

Zhang, H., Van der Lee, T., Waalwijk, C., Chen, W.Q., Xu, J., Xu, J.S., Zhang, Y. and Feng, J., 2012. Population analysis of the Fusarium graminearum species complex from wheat in China show a shift to more aggressive isolates. PLoS One 7: e31722. 
Zhang, H., Zhang, Z., Van der Lee, T., Chen, W.Q., Xu, J., Xu, J.S., Yang, L., Yu, D., Waalwijk, C. and Feng, J., 2010. Population genetic analyses of Fusarium asiaticum populations from barley suggest a recent shift favoring 3ADON producers in southern China. Phytopathology 100: 328-336.
Zhang, J.B., Wang, J.H., Gong, A.D., Chen, F.F., Song, B., Li, X., Li, H.P., Peng, C.H. and Liao, Y.C., 2013a. Natural occurrence of fusarium head blight, mycotoxins and mycotoxin-producing isolates of Fusarium in commercial fields of wheat in Hubei. Plant Pathology 62: 92-102.

Zhang, L.P., Wang, J.S., Zhang, C.L. and Wang, Q.M., 2013b. Analysis of potential fumonisin-producing Fusarium species in corn products from three main maize-producing areas in eastern China. Journal of the Science of Food and Agriculture 93: 693-701. 
